\title{
EL PROBLEMA DEL DÉFICIT DE RECONOCIMIENTO DENTRO DE LAS INSTITUCIONES DE ENSEÑANZA SECUNDARIA DEL URUGUAY
}

\author{
THE PROBLEM OF RECOGNITION DEFICIT \\ INSIDE THE HIGH SCHOOL INSTITUTIONS OF URUGUAY
}

\author{
Marcelo Gambini' ${ }^{15}$
}

\section{RESUMEN}

En este trabajo se propone realizar un estudio sobre el problema del déficit de reconocimiento dentro de las instituciones de Educación Secundaria del Uruguay, a partir de la lectura de Hegel (1805-1806/1984; 2015) y Honneth (2009), bajo el entendido de que es posible comprender el problema del mal funcionamiento de las instituciones de Educación Secundaria como una patología de lo social. En tanto los problemas de estas instituciones remiten a un déficit en la racionalidad que las orienta, ello afecta la gramática de reconocimiento intersubjetivo (docente-estudiante), dando lugar a un déficit de reconocimiento de la autoridad docente y de aquellos estudiantes que no se adecuan a las exigencias institucionales.

Palabras clave: Déficit de reconocimiento, Educación secundaria, formación

\begin{abstract}
In this paper it's proposed to carry out a study on the problem of the recognition deficit within the High school Institutions of Uruguay, from the reading of Hegel (1805-1806/1984; 2015) and Honneth (2009), under the understanding that is possible to comprehend the problem of the malfunction of the High school institutions as a pathology of the social. While the problems of these institutions refer to a deficit in the rationale that guides them, this affects the grammar of intersubjective recognition (teacher-student), resulting in a deficit of recognition of the teaching authority and those students who do not adapt to the institutional requirements
\end{abstract}

Keywords: recognition deficit, High School, formation.

\section{¿POR QUÉ SE HACE NECESARIO PENSAR NUEVAMENTE LOS PROBLEMAS DE LAS INSTITUCIONES DE EDUCACIÓN SECUNDARÍA?}

En la actualidad se habla, en distintos medios de comunicación, de la existencia de varios problemas en las instituciones de Educación Secundaria. Estos problemas tienden a resolverse a partir de soluciones instrumentales: seguimiento de trayectorias educativas, tutorías, posibilidades de cursada especial, etc. Tales soluciones son instrumentales porque buscan resolver los problemas brindando espacios, instrumentos,

15 Licenciado en Psicología; Maestrando en Psicología Clínica de la Facultad de Psicología, Udelar; Maestrando en Filosofía Contemporánea en la Facultad de Humanidades y Ciencias de la Educación, Udelar; Docente Ayudante grado 1, en el Instituto de Psicología Clínica de la Facultad de Psicología, Udelar; Docente Titular del curso de Ética profesional y legislación aplicada a la profesión en el Instituto Universitario Asociación Cristiana de jóvenes. 
seguimientos informáticos. Lo cual, si bien se plantean como medios para mejorar la educación, no problematizan el núcleo duro del problema educativo, que quizás no sean los aprendizajes en sí, sino un déficit de reconocimiento en la relación docente-estudiante.

Si partimos de la observación del aula, notamos, cada vez más, que hay estudiantes que parecen no reconocer al docente y a la normatividad de la institución, de tal modo que parecen "impermeables" a retos, llamados de atención, propuestas de trabajo, etc. A partir de esta observación, se considera que un problema acuciante para las instituciones de Educación Secundaria (quizás uno de los más graves) es el déficit de reconocimiento en la relación docente-estudiante, el cual no parece resolverse al introducir ciertas modificaciones del régimen normativo u otros espacios para el aprender, ya que ello no necesariamente garantiza nuevas modalidades de interacción ni de reconocimiento intersubjetivo.

Es curioso notar como las medidas aplicadas a los problemas de la educación (repetición, abandono liceal, problemas de conducta) no suelen incorporar la necesidad de propiciar nuevas modalidades de reconocimiento intersubjetivo, sino que más bien se preocupan en la motivación de mediante el desarrollo de proyectos, el uso de las tic, etc.

Por supuesto, no se niega que es fundamental motivar a los estudiantes a nuevos aprendizajes. El problema es que muchos alumnos que no parecen interesarse ${ }^{16}$ por nada ${ }^{17}$, aun cuando se intente proponer otros temas o modalidades de trabajo, entonces, ¿será que el problema de la educación se puede reducir solamente a la falta de motivación o la dificultad por planificar una clase?

Por otra parte, ante este problema, cuando se realizan estos intentos por favorecer el acto educativo, muchas veces se equipara, erróneamente, educación con Instituciones de Educación, por lo que, en el fondo, ¿de qué se habla?

Si vamos al núcleo del concepto de educación, a partir de la lectura Hegel (2015) podemos comprender que la misma se liga a la formación del sujeto, en tanto refiere a un proceso de transformación de la materia, la cultura y la sociedad, que se da en la historia, lo que implica una relación de reconocimiento.

\section{Como plantea Friedemann:}

Ser sujeto...es hacerse sujeto. Se trate del sujeto individual o colectivo, no somos algo ya hecho, sino que nos hacemos...Devenimos un ser otro....La principal mediación por la que nos realizamos y nos formamos es el trabajo. Al trabajar le imprimimos nuestra marca...al material de trabajo... Al trabajar la madera, transformamos esa madera, le damos forma de silla. ...El resultado, el producto de nuestro trabajo, es nuestro arte, es el sujeto en el objeto. Mi trabajo, el yo, en la silla" (2010, s.n.)

Cuando eso ocurre, según Hegel (2015), al reconocernos en el producto del trabajo al que le dimos forma, nos realizamos como sujeto.

Si en dicha relación de reconocimiento nos formamos al trasformar al mundo, quien estudia también se forma al trasformar materiales, conceptos, procedimientos matemáticos, etc. Aunque en su caso, tal formación está mediada por otra relación, la que se establece con el docente.

Si el docente se posiciona como un agente del saber a ser reconocido, el estudiante, al reconocer al docente como un agente de saber, es capaz de responder a esa relación transformándose en un otro que se reconoce así mismo como un sujeto en relación al saber, como estudiante. Esta dialéctica de reconocimiento propicia procesos de modificación de objetos, conceptos, lenguaje, mundo. Mientras el estudiante se forma, el docente debe reconocer al estudiante como un sujeto en el mundo, con saberes, conceptos, ideas en formación. Sólo así se da una dinámica transformativa en la que, al reconocer el lugar del saber (por parte del estudiante) y al sujeto en formación (por parte del docente), quien se forma se reconoce en

16 Según algunas observaciones e intercambios realizados en Montevideo con docentes, los estudiantes muchas veces se presentan "desinteresados por todo". Según los españoles Martínez, Fernández Enguita y Riviére Gómez, (2010), el desinterés se produce porque en secundaria el proceso educativo tiende a centrase en la enseñanza de la asignatura más que en el proceso de aprendizaje del estudiante o en su u orientación, por lo que el vínculo entre alumno y profesor se debilita mucho, haciendo que los estudiantes se sientan "desconectados de los profesores". Ante este planteo presentamos un matiz, pues es notorio ver en Montevideo como los docentes tratan de enfocarse en los procesos de aprendizaje y, aun así, hay estudiantes que parecen desconectados.

17 Según la Tercera Encuesta Nacional de Juventud (2013) la falta de interés uno de los motivos más mencionados de abandono liceal (Pereira, 2015). 
una relación con el saber y quien educa reconoce que el otro participa de un proceso en que ya preexistiría cierta relación con el saber. A partir de allí, gracias al reconocimiento, el estudiante participa de procesos de intercambio normado, de modo que transforma su forma de vida.

Sin embargo, si no reconoce ese lugar de saber, surge un problema: se produce un déficit de reconocimiento del saber, a partir del cual el lugar del saber agenciado por el lugar docente queda destituido. Con ello, el lugar de la normatividad que sustenta la relación docente-alumno queda forcluido y la relación con los objetos trastocada.

La destitución del lugar del saber, al bloquear la normatividad que sustenta las relaciones interpersonales, impide el ejercicio de racionalidad ya que, si la misma implicaba una puesta a la razón, tal razón era posible sólo en una relación normativa con el saber. Si esta relación no es reconocida, entonces, se impide la razón como un medio para el saber. Así, si el estudiante no se relaciona con el saber y la normatividad, éste aparece dislocado. Se presenta como desordenado, ruidoso, desorganizado.

\section{¿Por qué ello es así?}

El docente no sólo representa el lugar del saber, sino también el de la norma, más ella se liga al espíritu de un pueblo. Es decir, que la norma se liga en la cultura, de modo que la función docente es propiciar una forma de vida: ser ciudadano del mundo.

Si ese lugar del saber se destituye, esa forma de vida a propiciar pasa a ser un imposible y el saber y la norma se viven como pura imposición. Esto produce que el estudiante reaccione, enfrente a la norma o la evada, como una manera de imponer otra forma de vida o de evitar ser trasformado a la forma de buena vida que de algún modo representaría el docente.

En esta situación, las instituciones de Educación Secundaria fallan, pues, a veces, no puede facultar al sujeto a comprender/se al mundo/ante el mundo, más su enfrentamiento permite que el individuo nos presente el "espíritu de un pueblo" (Hegel, 2015). El sujeto que nos enfrenta representa ese espíritu, aunque ello no es reconocido. Él suele ser visto por las instituciones de Educación Secundaria como un "sujeto ajeno", un sujeto patológico, en tanto no se adecua a la normatividad y en tanto que no puede ser reconocido por las Instituciones de Educación Secundaria como un sujeto que se educa, se produce un déficit de reconocimiento que da lugar al sufrimiento y a una posible estigmatización.

Si con la educación se da lugar a un "... alumbramiento que se sobrepone a la inmediatez natural para hacerse persona universal..." (Cortéz Sánchez, 2009, p. 81), con la lucha contra la educación parecería que se retorna a esa "inmediatez animal", el sujeto se presenta ante estas instituciones (para su mirada) en su aparente "animalidad"18 porque no parecería reconocer un lugar para sí en tales instituciones, un lugar donde pueda ser reconocido como algo más que un estudiante (un ser vivo, con afectos, vida e historia personal). Ahora bien, en la medida que en las instituciones de Educación Secundaria se introduce un déficit de reconocimiento, existe una "ceguera" para ver al otro o escuchar al otro ${ }^{19}$. Por ello, parecen predominar modos de relación que son captados como patologías. Esto es visible cuando el comportamiento de algunos estudiantes no se adecua al pacto normativo que impera en las instituciones de Educación Secundaria, lo que implica que tales sujetos se resisten a una imposición cultural e intentan vivir únicamente mediante su cultura. Por ello, cuando esta aparente "animalidad" se expresa, ya no es posible reconocer al estudiante en tanto tal, se lo capta como si fuera un "sujeto animalizado" (un sujeto que parece no adecuarse a las

18 La noción de "animalidad" busca: 1 ro) denunciar ciertas concepciones que parecerían obturan las posibilidades de visualizar otras modalidades de aprendizaje diferentes a las formales. 2 do) denunciar ciertos prejuicios que impiden, muchas veces, ver a los jóvenes como algo más que un conjunto de individuos que deben aprender, y que, si se resisten, es porque no están "preparados para el sistema".

19 A partir de algunos intercambios y observaciones preliminares realizadas en algunas instituciones de Montevideo sería posible considerar que, así como ha ocurrido en España, aquí en Uruguay "Tradicionalmente, el binomio educativo ha sido el profesorado y el alumnado" (Arjiz Tresguerras, 2000, p. 176), en que históricamente "el docente lo era todo y el discente un mero oyente. Incluso, hoy mismo, se sigue aplicando ..." (ídem) No sabemos si tal aplicación se presentaría en todas las instituciones del país y tampoco afirmamos que ella sea dominante para todos los docentes. Sin embargo, creemos que el enfoque tradicional tendría, aún hoy, cierta presencia. 
normas, no reconocer el lugar del otro-autoridad, que tiende a actuar por impulso). Con ello, se trastoca las relaciones y se estigma al estudiante ${ }^{20}$.

Sin embargo, hay que comprender que ese "sujeto animalizado" solo es visto de esta manera porque no se ajusta o se resiste a una imposición cultural. En el fondo, en tanto sujeto humano, ese estudiante lucha por la "liberación del espíritu respecto a su estado de inmediatez natural..." (Cortéz Sánchez, 2009, p. 82). Esta liberación implica que el otro lo reconozca como sujeto humano y no sólo en su aparente "animalidad". El problema es que, desde las instituciones de Educación Secundaria, se tiende a comprender lo humano desde una ligazón a la cultura universal, de modo que para reconocerlo humano no alcanzaría que éste exprese su afecto, sino también debe expresar una relación a la normatividad reinante en estas instituciones y a esa cultura universal.

Si existe un déficit de la relación con la normatividad, no es posible que a través del ámbito educativo se establezca en el pensamiento del hombre una identidad con el mundo que lo rodea. Por ello, el individuo no puede hallar entonces ante sí "...el ser del pueblo, como un mundo acabado y fijo al que se incorpora." (Hegel, 1980, p. 71), no puede apropiarse este ser sustancial, de modo que este ser se convierte en su modo de sentir (en puro afecto).

Cuando el sentir predomina sobre la posibilidad del reconocimiento del otro, no es posible que por la educación la persona salga de lo natural y oriente su deseo mediante la búsqueda de actividades o una profesión que le permita ser reconocido por los otros y ante los otros. El papel de las instituciones de Educación Secundaria ante el deseo de reconocimiento es central, pues éstas deben permitir que los cuerpos se transformen mediante procesos de reconocimiento. El problema es que, si los individuos no se reconocen entre sí como seres humanos, sólo queda lugar para la lucha.

Mientras ello se da, al ver las acciones orientadas a mejorar la educación, parece no existir una mirada hacia el problema del déficit de reconocimiento docente-estudiante y se busca generar acciones que minimicen los riesgos de repetición. El problema es que, si no se aborda esa relación de desconocimiento, tales medidas pueden ser insuficientes, pues si no se reconoce al otro es imposible aprender algo con él.

\section{CONSECUENCIAS DE LA IMPOSIBILIDAD DEL APRENDER}

Si el aprender se torna imposible (o se lo percibe como imposible) la actividad humana no puede superar la inmediatez, pues no la niega, de modo que mediante la educación no sería posible superar la "animalidad" (ese aparente estar o presentarse en una relación cerrada y alienante con la "naturaleza" - con su cultura-). Sin embargo, si bien esta "imposibilidad" parecería clara, es necesario advertir que, fuera de las instituciones de Educación Secundaria, la propia acción del joven afirma su historicidad, lo que se liga a la condición de pueblo (Novelli, 2001).

Si el joven es fruto de su actividad de formación, y si la formación incluye lo educativo más no se homologa a ello, el joven sigue siendo fruto de una actividad de formación. Más si él no participa del sistema de educación formal (en particular de los liceos), si bien él puede participar de la vida del pueblo en general -de la cultura universal-, ello no se le reconoce, y en tanto no se reconoce se lo mira como excluido del mundo.

A pesar de ello, como dice Novelli (2001), todo hombre aprende del mundo y representa para sí lo experimentado de modo que, si bien desde las instituciones de Educación Secundaria puede afirmarse que este "chico no aprende", o "no ha aprendido nada", tal chico aprende de su mundo, es capaz de participar de la vida del pueblo, por lo que es un sujeto en el mundo.

Sin embargo, tal aprendizaje del mundo parece no ser suficiente, pues el sujeto no es sólo en sí, sino que además es en sí para otro, un otro sin el cual puede estar limitado en su aprendizaje, pues para ser sujetociudadano necesita de la educación, lo cual refiere, en parte, a su trayectoria por las instituciones educativas.

El problema es que su trayectoria educativa no debería centrarse en "una mera transmisión o una mera recepción, pues el individuo también ya sabe y ofrece, dejando de ser un receptor pasivo" (Novelli, 2001,

20 No afirmamos que ello siempre se produzca. Sin embargo, se ha observado en más de una ocasión entre proceso de estigmatización. A pesar de ello, es importante destacar que hay docentes que se cuestionan estos procesos y buscan generar modalidades diferentes de interacción con los estudiantes. 
p. 72). ${ }^{21}$. Por ello, cuando al sujeto no se le reconoce su lugar de "creador", de participe del saber, siente un déficit de reconocimiento, y ello afecta la relación con el docente.

En teoría, la educación debería proporcionar:

...el segundo nacimiento del individuo porque lo torna autónomo, señor de sí... La autonomía es una conquista del individuo porque este precisa adherir a la propuesta del pueblo y renunciar a sus particularidades y exclusivismos... Por lo tanto, la educación dice respecto a la existencia de los individuos y de cómo estos vienen a ser individualidad colectivizada... (Novelli, 2001, p. 72-72). ${ }^{22}$

Sin embargo, tal proceso puede fallar, y cuando falla es porque está obturado el reconocimiento del estudiante como sujeto en el mundo, de modo que, al no sentirse reconocido, se excluye (y es excluido), por lo que se le dice que "no aprende". Sin embargo, es falso que no aprende, pues mientras viva en comunidad aprende, aunque ello depende un proceso mediado por alguien. Ahora bien, si falla el aprendizaje formal, el sujeto no puede apropiarse de la cultura general de la que participan los pueblos, por lo que su conocimiento es limitado, ya que "...conocer es hacer suyo el conocimiento constituido por otros pueblos." (Novelli, 2001, p. 75). ${ }^{23}$

\section{A MODO DE CIERRE}

Si el estudiante no se adecua a las instituciones de Educación Secundaria, su libertad subjetiva parece no ajustarse en el querer racional universal de tales instituciones, aunque en realidad no por ello deja de aprender. El problema es que pierde la posibilidad de gozar de la libertad para poder circular en esas instituciones como un sujeto que aprende. Por dicha razón, frente a este déficit de reconocimiento, el estudiante reacciona, pues se siente menospreciado. Quizás por ello, es reconocido por la institución como "animalidad", un no sujeto, o un sujeto desordenado, indisciplinado, o que se opone al "sistema".

Tal "animalidad" denuncia un estigma, pues no reconoce otros procesos de aprender que no sean el aprender formal. Ello produce sufrimiento, pues al estudiante se lo considera un sujeto no libre, en tanto no está en concordancia con el "espíritu del pueblo", por lo que se supone que no sabe de sí. Ante este problema, la posibilidad de que se genere la desafiliación es enorme, más cuando ello se intenta resolver de manera instrumental. El déficit de reconocimiento docente-estudiante no se resuelve con tutorías, arreglos en el horario, planes de recursada especial, etc. Al estudiante no es que le cueste aprender (o por lo menos no sólo le cuesta aprender) sino que, además, a veces, es visto como alguien que no aprende, y en tanto no se lo reconoce como alguien con capacidad de aprender, es afectado por ello. Por otro lado, muchas veces, estos sujetos no reconocen a su vez el lugar del saber encarnado en el docente o se oponen a él, ello los impulsa a la lucha o a una posición evitativa que dificulta conocer su posibilidad de aprender. Su enojo, su incomodidad son vistas como patología, por lo que los estigmas pueden operar signando esos cuerpos como "animalidad". Existe así un circuito de retroalimentación negativo, un circuito de mutua exclusión. Mientras el estudiante destituye el lugar del saber, al mismo tiempo, tras su accionar, se lo destituye de su lugar de aprender.

En estas condiciones, la educación no puede armonizar la relación interpersonal, y en muchos casos el efecto de esa falta de armonía en una lucha que termina por impulsar al estudiante a su exclusión. Con ello, no se le posibilita al joven salir del "estado de naturaleza" (Hegel, 2015).

Como la educación supone una relación con el saber y la normatividad (respeto a la autoridad, disciplina) su disfuncionamiento es visto como un obstáculo para que el sujeto se convierta en otro, por pleno uso de su libertad.

Lo curioso es que, ante ello, más que intentar trabajar sobre los déficits de reconocimiento, muchas veces se trabaja sobre los déficits de rendimiento, de modo que se trastocan las posibilidades de resolver el problema, ya que se cree que el problema de quien no se educa es su dificultad por aprender, cuando puede ser otra cosa, su dificultar por participar en un circuito de reconocimiento positivo, donde pueda sentir que es

21 La traducción de la cita del portugués al español es nuestra.

22 La traducción de la cita del portugués al español es nuestra.

23 La traducción de la cita del portugués al español es nuestra. 
reconocido y que puede reconocer al otro. Este aspecto es central para comprender la posible utilidad de los castigos. Como dice Cortés Sánchez (2009) al citar a Hegel: "La finalidad de los castigos no es la justicia como tal, sino que es de naturaleza moral, subjetiva; intimidación a la libertad aún asida a la naturaleza y elevación en la conciencia y voluntad de lo universal" (p. 81). Intimación que busca que el sujeto reconozca la autoridad, pero si el sujeto destituye tal reconocimiento, el castigo no produce efecto. Si el castigo no cumple su función, quizás la manera de favorecer un reconocimiento deba ser de lo afectivo, mostrando lo humano tras el saber. Quizás solo así el joven logre reconocerse como alguien que aprende, al reconocer a un otro humano detrás del saber.

\section{REFERENCIAS}

Arjiz Tresguerras. J. C. (2000) La vida escolar. Participación en la comunidad educativa. En: (2000) La Educación Secundaria Obligatoria a debate. Situación actual y perspectivas, 173-181. Ministerio de Educación y Cultura. Secretaría General de Educación y Formación Profesional. Centro de Investigación y Documentación Educativa. España. Recuperado de https://sede.educacion.gob.es/publiventa/detalle.action?cod=466

Cortéz Sánchez, E. M. (2009) G.W. F. Hegel y la Fundamentación Filosófica de la Educación en Derechos Humanos., Magistro. Revista de la Maestría en Educación de la Vicerrectoría de la Universidad Abierta y a Distancia, 1(5), 77-87. Recuperado de https://www.academia.edu/1156800/WF HEGEL Y LA FUNDAMENTACI\%C3\%93N FILOS\%C3\%93FICA DE LA EDUCACI\%C3\%93N EN DERECHOS HUMANOS

Friedemann. S. M. (2010) De la dialéctica hegeliana a la educación popular en Antonio Gramsci y Paulo Freire. Revista Diaporías. Buenos Aires: Universidad de Buenos Aires, (9), s.n. Recuperado de https://critica.jimdo.com/analisis-dela-educacion/de-la-dialectica-hegeliana-a-la-educacion-popular-en-antonio-gramsci-y-paulo-freire/

Gambini M. (2019). Vida animal, vida humana: entre el deseo animal y el papel de la educación ante el deseo de reconocimiento. Ariel. Revista de Filosofía, Red Filosófica del Uruguay, Montevideo, Latindex, (23), 45-48. Recuperado de https://arielenlinea.files.wordpress.com/2019/07/vida-animal-vida-humana-entre-el-deseo-animal-y-el-papelde-la-educacic3b3n-ante-el-deseo-de-reconocimiento.pdf

Hegel G. W. F. (1805-1806/1984). Filosofía real. México D. F: Fondo de Cultura Económica.

Hegel G. W. F. (2015). Escritos pedagógicos. México: Fondo de Cultura Económico.

Honneth A. (2009). Crítica del agravio moral. Patologías de la sociedad contemporánea. Buenos Aires: Fondo de Cultura Económica. Universidad Autónoma Metropolitana.

Kojève, A. (2016). Introducción a la lectura de Hegel. Madrid: Trotta

Martínez L. M; Fernández Enguita M. y Riviére Gómez J. (2010). Desenganchados de la educación: procesos, experiencias, motivaciones y estrategias del abandono y del fracaso escolar. Revista de Educación. número extraordinario, 119-14. Recuperado de http://www.revistaeducacion. educacion.es/re2010/re2010 05.pdf

Novelli, P. G. (2001). O conceito de Educação em Hegel. Interface - Comunic, Saúde, Educación, (9), 65-88. Recuperado de http://www.scielo.br/pdf/icse/v5n9/05.pdf

Pereira S. (2015). Una mirada al construccionismo del programa LabTeD de Plan Ceibal en educación media (Tesis de grado). Universidad de la República. Facultad de Ciencias Sociales. Departamento de Sociología. Recuperado de https://www.colibri.udelar.edu.uy/jspui/bitstream/20.500.12008/10034/1/TS PereiroEmiliano.pdf

Fecha de Recepción: 22/10/2019

Fecha de Aceptación: 23/11/2019 